
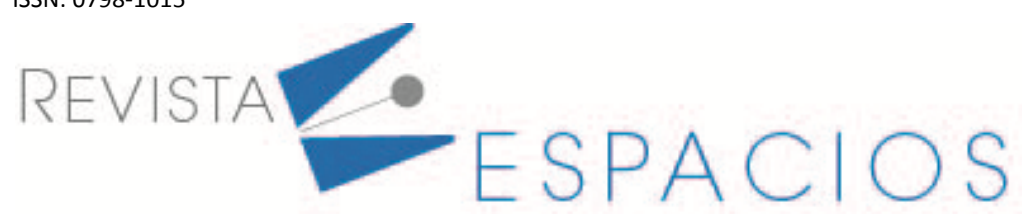

\title{
Strengthening critical thinking through reading strategies in higher education students from Monteria, Colombia
}

\section{Fortalecimiento del pensamiento crítico a través de estrategias de lectura para estudiantes de educación superior en Montería, Colombia}

\author{
GARCÍA CASTAÑEDA, María G ${ }^{1}$. \\ GUZMÁN BEJARANO, Dayan $A^{2}$. \\ PINTO DORIA, Lida $\mathrm{M}^{3}$. \\ VERGARA GUERRA, Dalis ${ }^{4}$
}

\begin{abstract}
Resumen
Este artículo describe como a través de la aplicación de estrategias lectoras se puede fortalecer el pensamiento crítico de los estudiantes. En la metodología se usaron el método mixto, un test diagnóstico, una entrevista semiestructurada y una estrategia pedagógica basada en las habilidades del pensamiento crítico de Facione. Los resultados mostraron que estas estrategias contribuyeron al desarrollo del pensamiento crítico.Se encontró una notable mejoría en la habilidad de explicación. En la estrategia del video,los estudiantes lograron ubicarse en un nivel alto o superior en casi todas las estrategias.

Palabras clave: pensamiento crítico, habilidades, lectura crítica

Abstract

This research aims to describe how students' critical thinking skills could be strengthened using reading strategies. In the methodology, quantitative and qualitative approaches were used, as well as a diagnostic test, a semi-structured interview, and a pedagogic strategy based on Facione's critical thinking skills. Results showed that all strategies contributed to strengthening critical thinking skills. It was also encountered a noticeable improvement in the explanation skill. In the video strategy, tudents obtained a high or superior level in almost all the skills.

key words: critical thinking, skills, critical reading
\end{abstract}

\section{Introduction}

This research study started due to the low level of critical thinking development from students who just join higher education. Learners faced difficulties managing thinking skills, e.g., interpretation, analysis, explanation, inference, comprehension, evaluation-reflection, and self-regulation; evident in their performance in class: a passive conception, no reflection, little knowledge of their environment, among others. These were some indicators of low level of critical thinking capacity. It was also observed that development of critical thinking was not encouraged in the classrooms as needed in today's world.

\footnotetext{
${ }^{1}$ Universidad Pontificia Bolivariana, Colombia. Email: maria.garciac@upb.edu.co

2 Universidad Pontificia Bolivariana, Colombia. Email: dayan.guzmanb@upb.edu.co

3 Universidad Pontificia Bolivariana, Colombia. Email: lida.pinto@upb.edu.co.

${ }^{4}$ Universidad Pontificia Bolivariana, Colombia. Email: dalis.vergara@upb.edu.co
} 
A diagnostic test, designed by the Language Center of Universidad Pontificia Bolivariana (UPB) based on Facione's List of the Core Six Critical Thinking Skills (CTS) (2013), and a semi-structured interview, were applied at the beginning of this study to identify the learners' critical thinking skills. The results from these instruments showed that first year students from Psychology, Social Communication and Journalism, Business Administration, Civil engineering, Industrial engineering, Agroindustrial engineering, Law, and Business administration programs at UPB Seccional Monteria (2019), were diagnosed with a low level of management of critical thinking skills (0-49\%) in comparison to the mean obtained in the National Assessment Scale (47.85\%), provided by the National Education Ministry in Decree 1290 from 2009. In the test, the samples merely achieved the highest value in interpretation skill, whereas the level of difficulty was the lowest compared to other critical thinking skills. Other scores demanding higher cognitive processes were below average.

This research was focused on designing some strategies that could help to improve this situation. Therefore, five strategies were designed considering Facione's critical thinking skills. Then, they were applied to 135 students from the Psychology and Law programs at Universidad Pontificia Bolivariana Seccional Monteria. Thus, the findings from this experiment gave a real and critical vision of students' performance in terms of critical thinking and reading comprehension.

\subsection{Previous studies related to critical thinking}

Nowadays, one of the most relevant goals for educators is to provide students with opportunities to find meaning, engage with concepts, and utilize logic arguments, so that they may get a deeper and more profound understanding of the world in which they live. Then, the question is, what methodologies can be useful to promote the development of students' critical thinking skills?

In regard to this topic, Facione (2007) emphasizes the relevance of using and practicing critical thinking in different contexts such as personal life, learning processes, workplace, and activities developed by and with the community. He states that cognitive skills and dispositions are significant when developing critical thinking. Also, he defines critical thinking as "the process of purposeful, self-regulatory judgement". (Facione,1990).

According to Facione (2013), there are altogether six core skills involving critical thinking processes, known as interpretation, analysis, evaluation, inference, explanation and self-regulation skills. He defines them as follows: (1) Interpretation is to comprehend and express meaning or significance of a wide variety of experiences, situations, data, events, judgements, conventions, beliefs, rules, procedures, or criteria.(2) Analysis is the identification of other forms of representations intended to express belief, judgement, experiences, reasons, information, or opinions.(3) Evaluation is concerned with the credibility assessing, credibility of statements or other representations which are accounts or descriptions of a person's perception, experience, situation, judgement, belief, or opinion.(4) Inference means to secure elements needed to draw reasonable conclusions. (5) Explanation deals with the justification of a reasoning in terms of the evidential, conceptual, methodological, logical, and contextual considerations upon which results were based. (6) Self-regulation is a self-consciously monitoring of one's cognitive activities, the elements used in those activities, and the results deduced; particularly by applying skills in analysis, and evaluation to one's own inferential judgements with a view toward questioning, confirming, validating, or correcting either one's reasoning or one's results. ( Facione, 2013).

He also assures that to become a critical thinker, an individual should develop their capacity to understand surrounding phenomena which is "only possible when a person has acquired competences such as: observing, classifying, organizing, analyzing, inferring, and others". He also states that every institution should strengthen analytical thinking so that learners could be able to observe the whole, its parts and the interrelationships among them. Moreover, he thinks that a critical thinker is not only able to evaluate everything around him but the 
individual has also the capacity to self-evaluate evidence of a great metacognition in what he does or thinks (Facione, 2007, p.5). He defines inference as the ability to show reasoning results in a coherent, reflexive, and solid way (p.5).

Additionally, Halpen (1998) believes that critical thinking "is the kind of thinking involved in solving problems, formulating inferences, calculating likelihoods, and making decisions". Besides, Paul and Elder (2004) mention that critical thinking is related to how people think about any subject, problem, or content. He added that they may improve their quality of thinking by using structures inherent in thought.

It is true that schools and universities often foreground repetition and memorization like Sterberg (2003) stated in his research study. Furthermore, he ascertains that retrieving data in certain cases is necessary and useful for living. Nontheless, critical thinking abilities should be developed, as well. Wilson(1997) discusses the multiple complexities and new realities of the world and how they have been taking a place in our lives. "He considers that those realities are not only in the economy but also in the environment, in the social-realities with profound implications for teaching and learning" (p. 1).

In short, it is the responsibility of educational institutions to promote and develop students' critical thinking abilities like analysis, interpretation, inference, evaluation, synthesis, among others. In addition, teachers should teach usable information that students can transfer and use into their lives and promote actions in and out the classroom that lead students to think, reflect, and make decisions allowing them to be responsible citizens.

\subsection{Critical thinking and reading skills}

According to Molly,W. (2014), reading is a fundamental part of academic education and it helps to enhance critical thinking in terms of reasoning and writing. His findings reported low satisfactory improvement in these two learning skills during the four years of higher education. This is a problem faced by all Colombian universities, as explained in the IV International Seminar on Research in the Quality of Education organized by the Colombian Institute for the Promotion of Higher Education (ICFES) in Bogota, 2013. A low level of academic progress was reported in this event, especially from students who refused to take courses requiring extensive reading and writing assignments. Another scholar, Aguilar (2000), contends that nowadays students are lacking creativity and criticality, essential skills to develop this purpose. Furthermore, his study also showed that young people encountered problems in reading comprehension related to analyzing, comparing, grouping, and synthesizing in higher education.

Cassany, D. (2003), assures that critical reading is complex, and it demands the highest levels of comprehension. He also suggests that an individual should develop three types of comprehension: literal, inferential and critical. In addition, other authors also state their assumptions about critical thinking: Garcia, M.G, (2016) in her research about critical thinking development mentioned that it is necessary to develop student's critical thinking using real life situations in which they must solve problems in their contexts by using specific pedagogical strategies like non-parametric didactics. Similarly, Taylor, J. (2012) stated that today, adoption of critical thinking strategies can also prepare students for the rigors of college life, as well as helping them to develop the necessary skills to compete economically in a global environment

In Colombia, the Ministry of National Education (MEN) has given orientations to follow Cassany's approach to enhance reading comprehension and critical thinking skills in public schools. Therefore, most Colombian schools have already included the reading comprehension levels mentioned above, in their study plans since 2009. 
Thereby, all above researchers agreed that developing critical thinking skills in students is necessary to cope with nowadays demands of a globalized society. As researchers, we think that it is pertinent to contribute to the development of students' critical thinking skills by designing strategies contributing not only to improve reading comprehension abilities but also to aid them to solve daily life situations and problems in their contexts.

\section{Methodology}

A mixed approach was used in this study. Hernández, Férnandez \& Baptista (2014) define the qualitative approach as a way to obtain understanding of underlying reasons, opinions, motivations, and dive deeper into the problem. They assure that it gives new insights and reveals new questions related to the interpretation process. On the other hand, the quantitative approach considers that knowledge should be objective and it is generated from a deductive process through numerical mediation and statistical analysis.

Considering this perpectives, a diagnostic test, a semi-structured interview, and a pedagogical strategy connected to reading and critical thinking skills were considered during the development of this research task as techniques for data collection.

The diagnostic test was made up of 50 questions selected from the Colombian Institute for the Evaluation of Education Public Data Base (ICFES,2018). These questions were chosen taking into account Facione's critical thinking skills. Its purpose was to determine students' critical thinking skills regarding reading comprehension as proposed in the objectives. The application of this test was the result of a process. It was made up of the following activities: (1) Selection and organization of questions. (2) Upload in the digital platform. (3) Summoning new incoming freshmen to take the evaluation. (4) Performance by students in ICT classrooms. (5) The test was graded automatically by the system.

It is relevant to mention that a measurement scale was assigned to measure students' performance in each one of the critical thinking skills. It was like this: (1) Low level (1.0-2.90), basic level (3.0-3.9), intermediate level (4.04.5), advanced level (4.6-5.0). This scale was proposed by Pontificia Bolivariana University. For this reason, the focus of this study is intentional and conditioned by the parameters established by this institution.

Once the results were attained, it was noticed that there were 135 students whose critical thinking skills were low. This is why, they became the target population of this research.

After applying the diagnostic test, students were questioned based on a semi-structured interview, connected to reading and critical thinking competence, and made up of 10 questions. The purpose of this technique was to recognize the students' previous knowledge about critical thinking and its relation to reading comprehension. Data from these interviews were analyzed using content analysis considering the points of view of Bardin's (2011) and Klipendorf's (2013) related to the analysis of the manifest and latent messages of a body of communicators.

After that, a pedagogic strategy was used in this research which consisted in: (1) Determining the kind of texts to be used. (2) Designing the five strategies including Facione's critical thinking skills: Interpretation, Analysis, Evaluation, Inference, Explanation, and Self-Regulation -all of them designed from significant resources in terms of content such as videos, infographics, riddles, specialized texts, and opinion articles.(3) Checking that all six abilities were significantly used in each one of the strategies.(5) Verification of student's schedule. (6) Ask for permits to faculty and teachers to apply the strategies, and finally, (7) Application.

The first strategy was an infographic whose topic was politics. The second was a reading comprehension related to human rights.The third one was a text based on riddles. The fourth one, was an opinion article about the peace treaty in Colombia, and the last one was a short video whose aim was assertive communication. Two hours were allocated for each strategy. There were 6 skills under study: interpretation, explanation, inference, evaluation, 
analysis and self-regulation. The measurement scale utilized in the diagnostic test, was also used after applying the strategies. The aim of these procedure was to analyze if there was any change after applying the strategies in relation to the diagnostic test.

A T-test was used in this study to compare the results between the diagnostic test and the results obtained after the application of the strategies as proposed in the specific objectives. Tae, $\mathrm{K} . \mathrm{K},(2015)$ defines the t-test as a type of statistical test used to compare the means of two groups. Besides, a multivariate analysis was used to see the interrelationship among the variables. Rencher, A (2002) considers that this kind of analysis is used when "measuring several variables and it is necessary to analyze the variables simultaneously, rather than isolate them and consider them individually". In this sense, this test and the multivariate analysis deals with quantitative data. On the other hand, the qualitative approach allows a deeper interpretation of students answers in relation to critical thinking.

\subsection{Population and sample}

The total number of students who took the diagnostic test was 492. But the target population of this study was 135 students whose ages range between 15 and 20 years. These pupils belong to Psychology, Social Communication and Journalism, Business Administration, Civil engineering, Industrial engineering, Agroindustrial engineering, Law, and Business administration programs. This sample was chosen due to the fact that they got the lowest average in the diagnostic test. Those students were attending language and culture courses, 4 hours a week at the Language Centre. This target population was intentionally conditioned by the parameters established by the Universidad Pontificia Bolivariana as aforementioned.

\section{Results}

Based on the objectives proposed in this research, the following results were obtained:

\subsection{Diagnostic test}

A diagnostic test was applied to all students who enrolled at UPB in the first semester of 2019. Regarding this test, it could be seen that they have a low level of competence regarding critical thinking skills as follows: It was noticed that learners achieved an average performance in the interpretation skill of $63.8 \%$. They got a result above the mean related to the questions evaluating this ability, whereas in the other five skills, the average oscillated between $0 \%$ and $49 \%$. This indicates that intervention is necessary to strengthen students' performance regarding critical thinking abilities.

\subsection{Semi-structured interview}

These are some of the results obtained based on the semi structured interview: $33 \%$ of students said that vocabulary was challenging and it was difficult to understand the texts. Other students commented that they had trouble when interpreting. $16.6 \%$ of students considered reading comprehension as a complex process while $5.5 \%$ said they do not like to read because they find academic texts difficult to understand. Furthermore, some participants in this study also assured that they had problems when doing textual analysis.

\subsection{Comparison between the diagnostic test and the strategies applied}

In this section a comparison among the different skills is presented taking into account Facione's critical thinking skills in the diagnostic test and the five strategies applied. 


\subsection{Interpretation skill}

Figure 1

Interptretation Skill Results

based on Levels of Competence

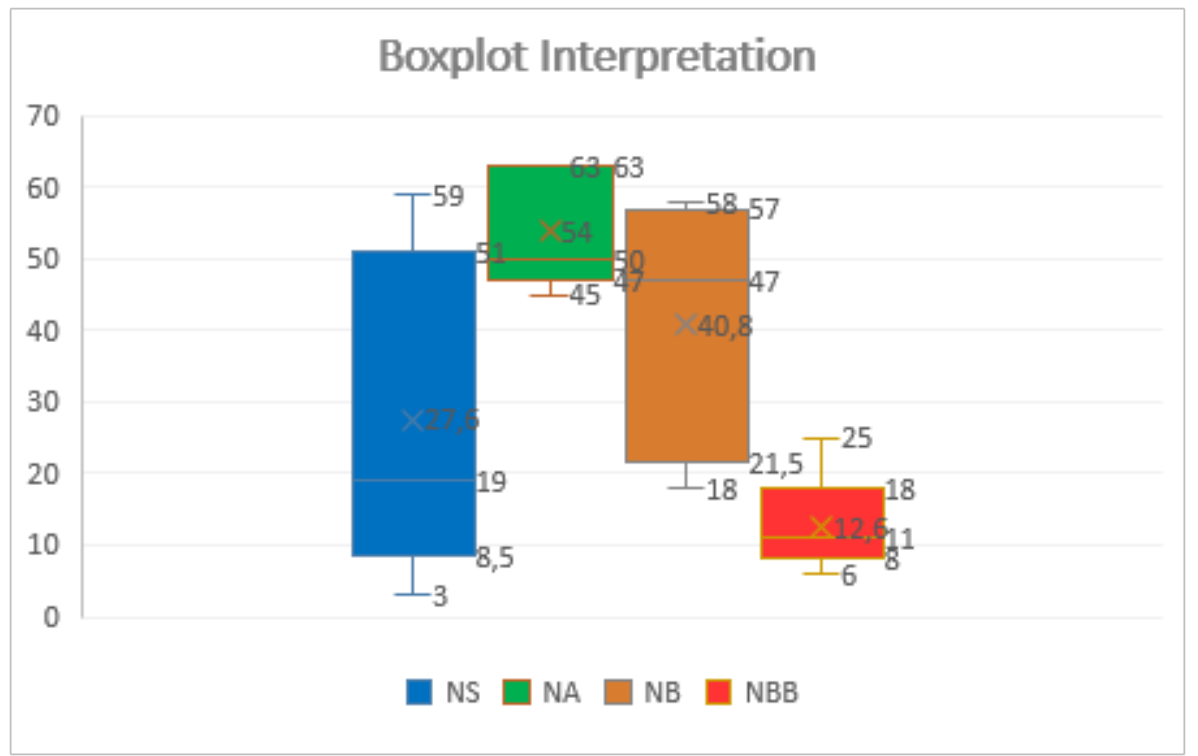

Source: Own-preparation

Figure 2

Comparison among the Diagnostic Test and Strategies taking into account the Interpretation Skill

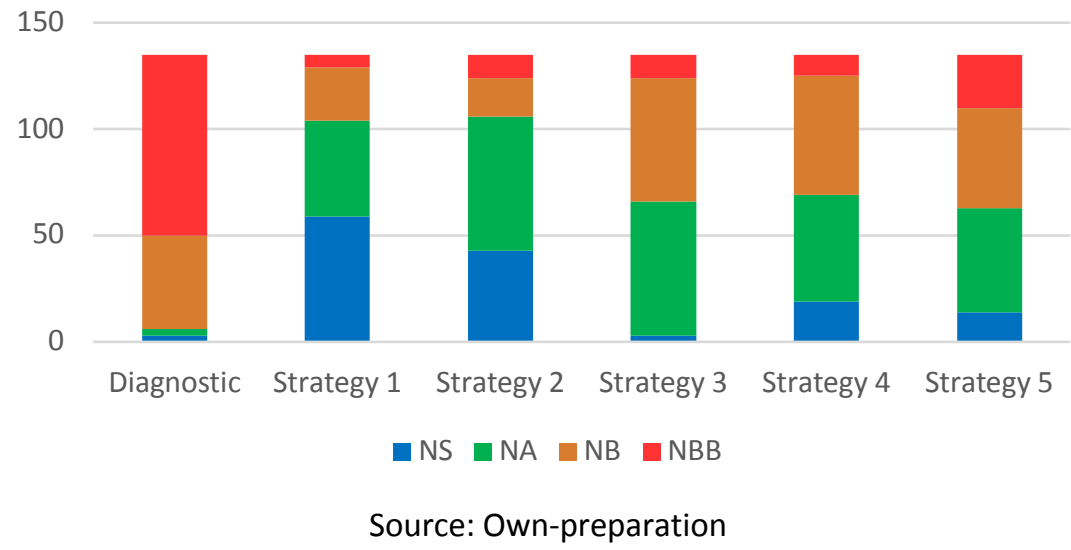

After applying the diagnostic test, it was found that 85 of 135 students (63\% of the target population) obtained a low level result in the interpretation competence. Once the five strategies were applied and the data analysis was done, it was found that the number of students in the low level result, decreased. On the other hand, it can be said that $44 \%$ of students achieved a superior level in strategy 1 (video). It can also be noticed that in the third strategy there were no students in a low level.

The boxplot was done taking into account the levels of performance (low, basic, high and superior). It excluded the diagnostic test and was based on the information gathered through the data analysis of the strategies used in this study. After applying the strategies, it was found that there was an average of 28 students placed in the superior level performance while the low level performance presented a decrease until reaching an average of 13 students. 
It could be observed after the application of strategies that some students showed a better comprehension of data, judgements, situations, and conventions included in the multimodal texts that students dealt with. This does not mean that there are no other students who need to continue improving this skill. In fact, to accomplish with Facione's idea of interpretation, learners still need to continue practicing the comprehension of beliefs, rules, procedures, and experiences so that they can deal with any kind of content as well as the ones included in this research.

\subsection{Analysis skill}

Figure 3

Analysis Skill Results based

on Levels of Competence.

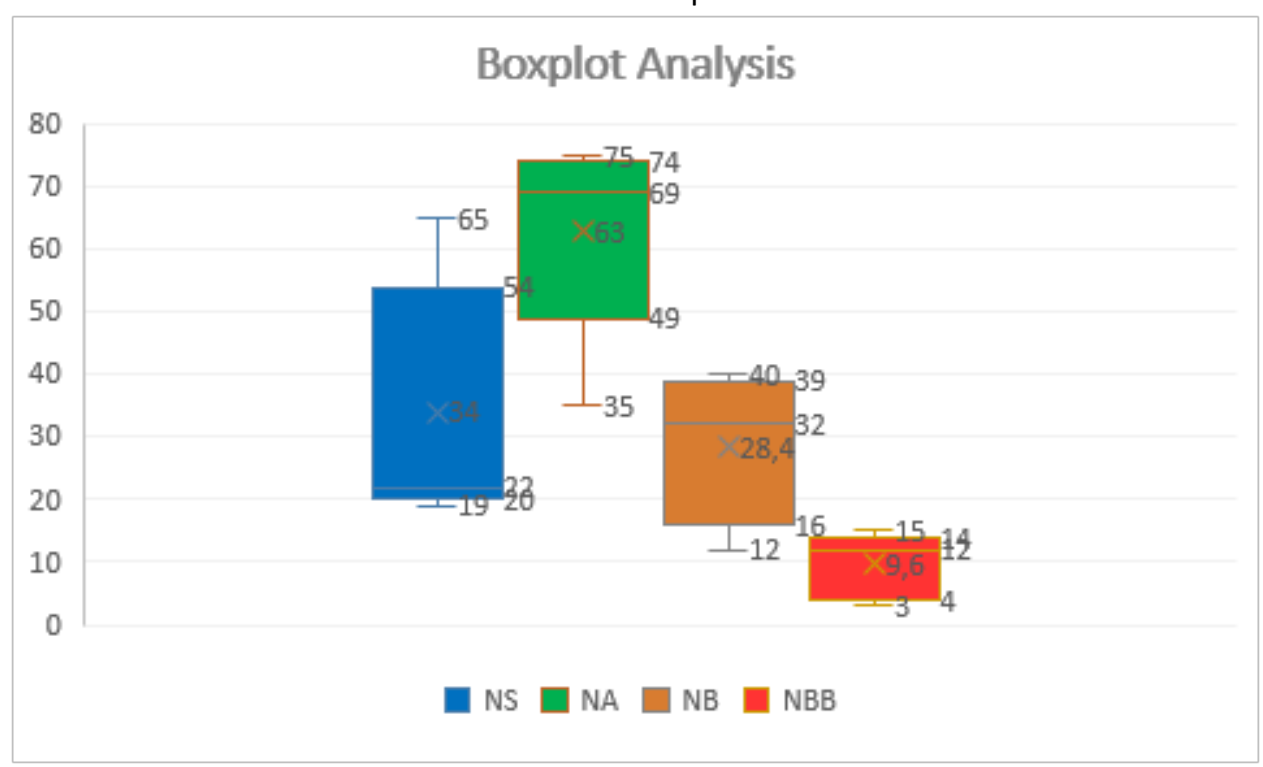

Source: Self-preparation

Figure 4

Comparison among the Diagnostic Test and Strategies taking into account the Analysis Skill.

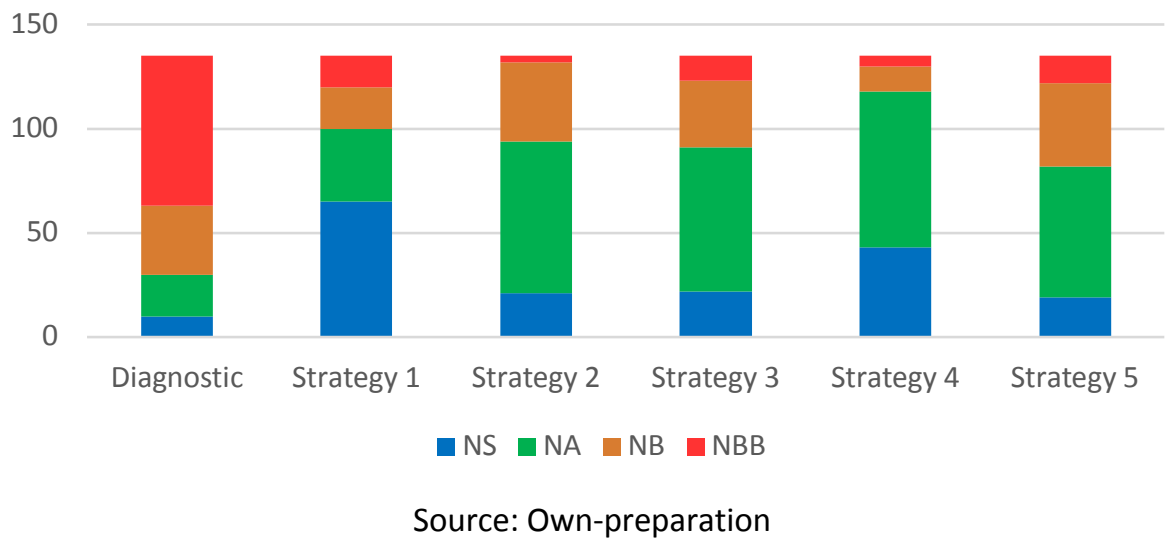

It was noticed that 72 out of 135 students (53\% of the target population) were located in the low level range after applying the diagnostic test in relation to the analysis skill. When using a bart chart analysis, the information evidenced that each one of the strategies applied, reached a minimum range of students. In relation to the superior level range, $48 \%$ of students reached it during the development of strategy 1. 
In average 63 students achieved a high level range in relation to the analysis skill, whereas an average of 10 students reached the low level range. The boxplot figure reflects therefore that 14 students correspond to $75 \%$ that are located in the low level.

The aforementioned information means that there was an improvement in the performance of learners when analyzing texts. It could be noticed after applying the strategies, that some learners could express beliefs, opinions and basic information in an appropriate way. But, there were others that still did not achieve a good performance. In general all students should continue identifying other forms of representation like reasons, beliefs, and experiences in reading comprehension as Facione's concept of analysis ability.

\subsection{Inference - Comprehension skill}

Figure 5

Inference-Comprehension Skill Results based on Levels of Competence.

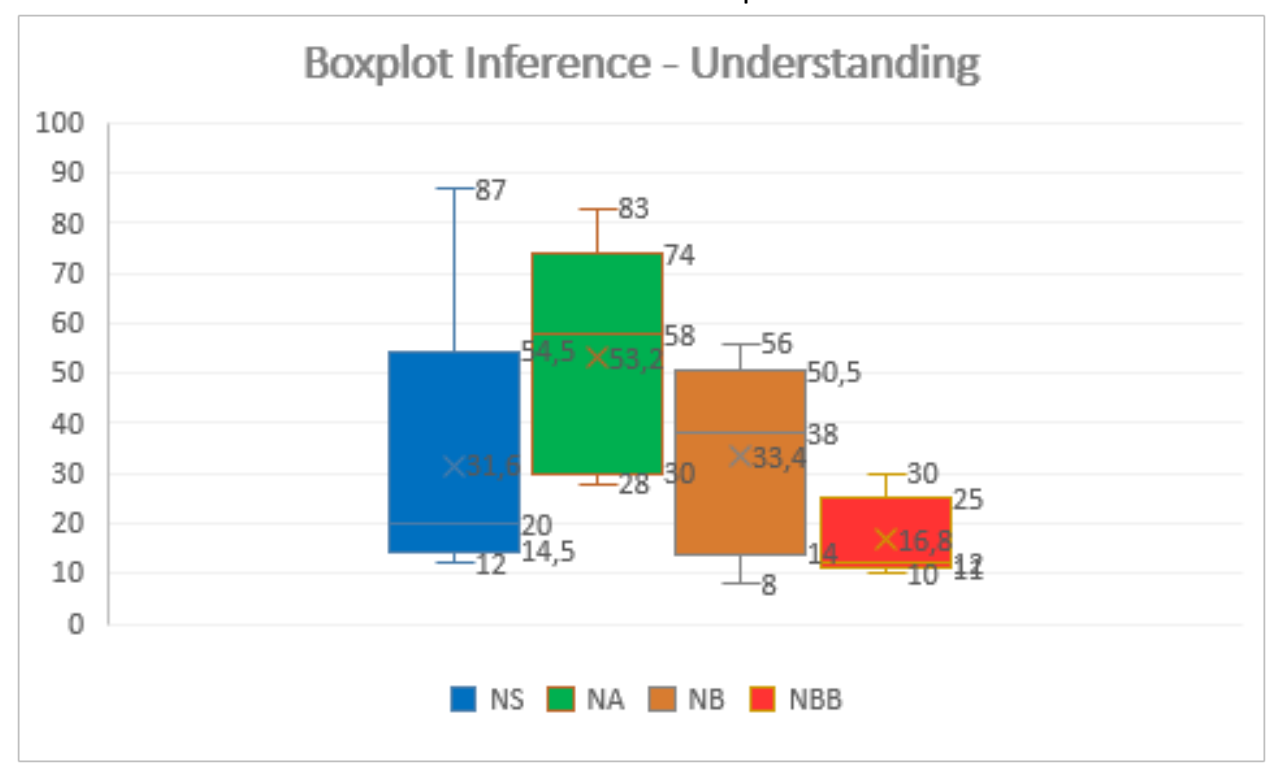

Source: Own-preparation

Figure 6

Comparison among the Diagnostic Test and Strategies taking into account the Inference-Understanding Skill.

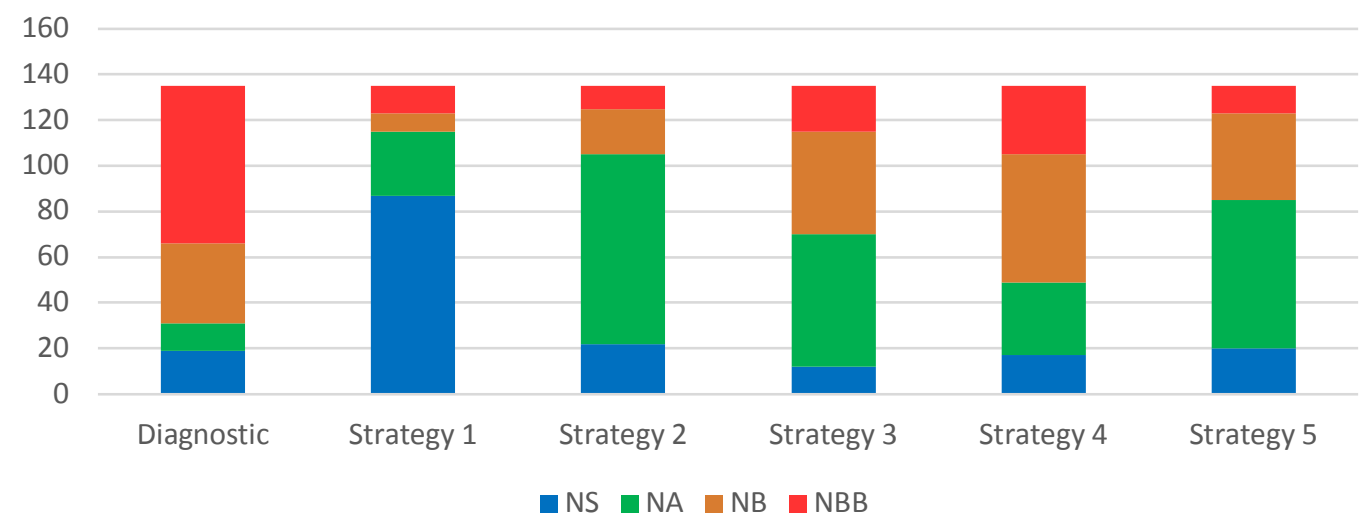

Soucre: Own Elaboration 
As a result of the diagnostic test, it was found that 69 out of 135 students ( $51 \%$ of the target population) obtained a low level performance in the inference skill. The bar graph reflects an increase in all strategies with respect to the high level, while in turn, it is presented a notable decrease in each one of the strategies corresponding to the low level. It is relevant to mention that strategy 1 , reached a percentage that coincides with $64 \%$ of students who achieved a superior level.

Based on the boxplot diagramam, it can be assured that the high level range is the most representative of this competence, with a number of 53 students. On the other hand, once the strategies were applied, the low level range represented a significative change, due to the fact that 25 students representing $75 \%$ of the target population, were placed in this level.

It was observed that almost half of the target population could answer questions, reasoning in a coherent and reflexive way. This is articulated with the Facione's idea of inference. However, it was also observed that some students did not reach a basic level. Though it is necessary that students continue practicing this ability so that they can gain a better performance.

\subsection{Explanation skill}

Figure 7

Explanation Skill Results based on Levels of Competence.

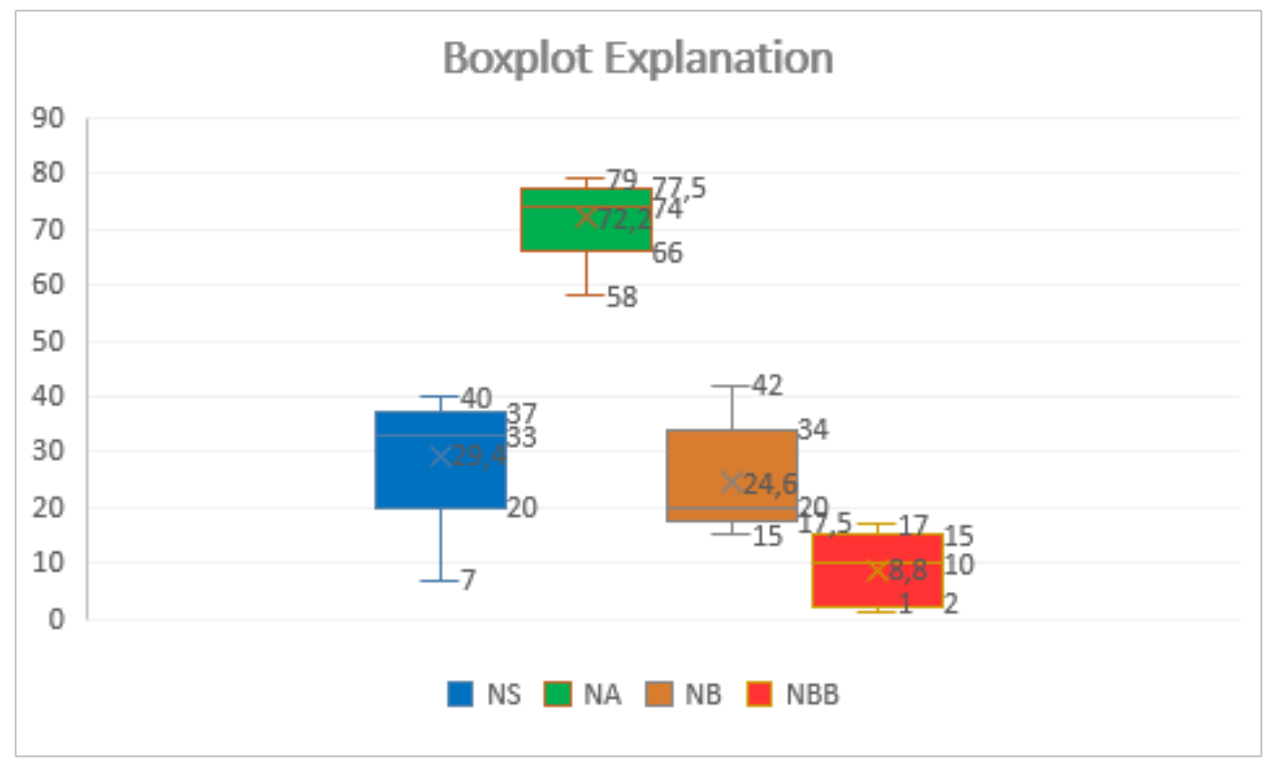

Figure 8

Comparison among the Diagnostic Test and Strategies taking into account the Explanation Skill.

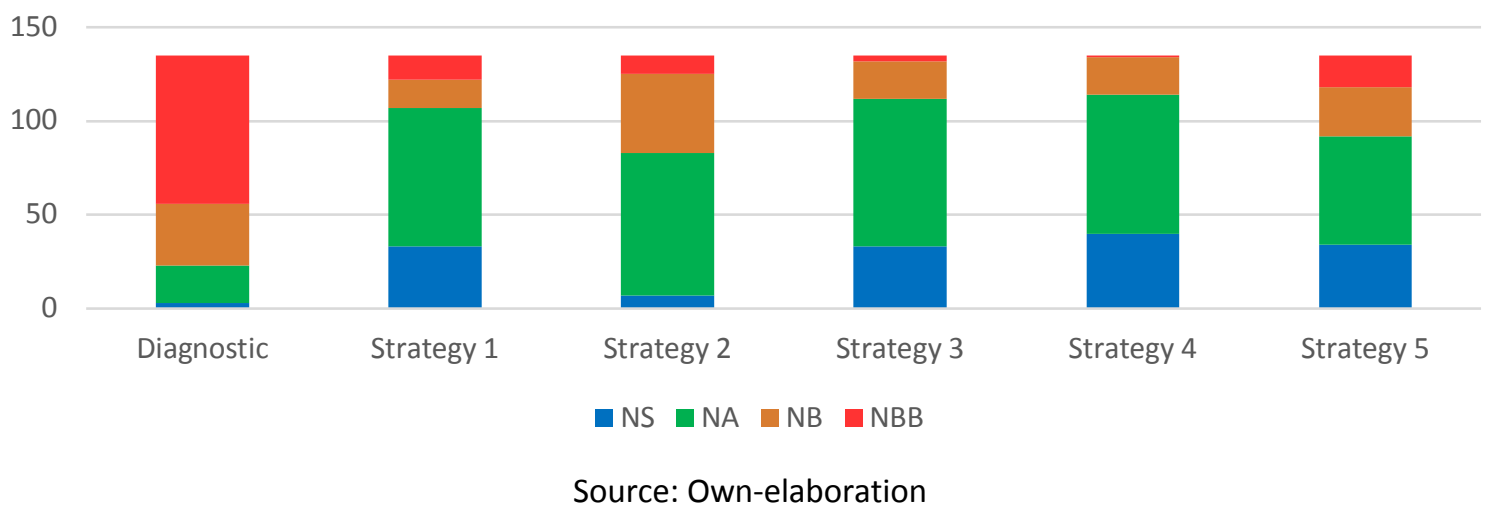


The application of the diagnostic test evidenced that $59 \%$ of the target population, corresponding to 79 students were located in the low level range. In contrast, the bart chart showed that all strategies applied after the diagnostic test, generated a significant increase in the high level range. It was just the opposite with the low level range, where values decreased in comparison with the number of students placed in this level. It was significant that just one student remained in the low level range after applying strategy 4 ( Infographic).

The boxplot figure confirms that the high level range presented the best positive change in relation to the strategies applied due to the average of students located in this level (72 students). In addition, the results favored this study, showing that 15 students that correspond to $75 \%$ of data were placed in the low level range. According to data presented in both figures, this skill showed a pretty good performance in terms of data.

As it is shown in figures 7 and 8 , a great number of students expressed their justifications and arguments in a coherent and logical way according to the type of questions included in the strategies.On the contrary, there were a few that presented problems to explain their ideas in a concise, coherent, and cohesive manner. They should organize their ideas in a macro structure to have a clear understanding of what they should say.

\subsection{Evaluation - Reflection skill}

Figure 9

Evaluation Skill Results based on Levels of Competence.

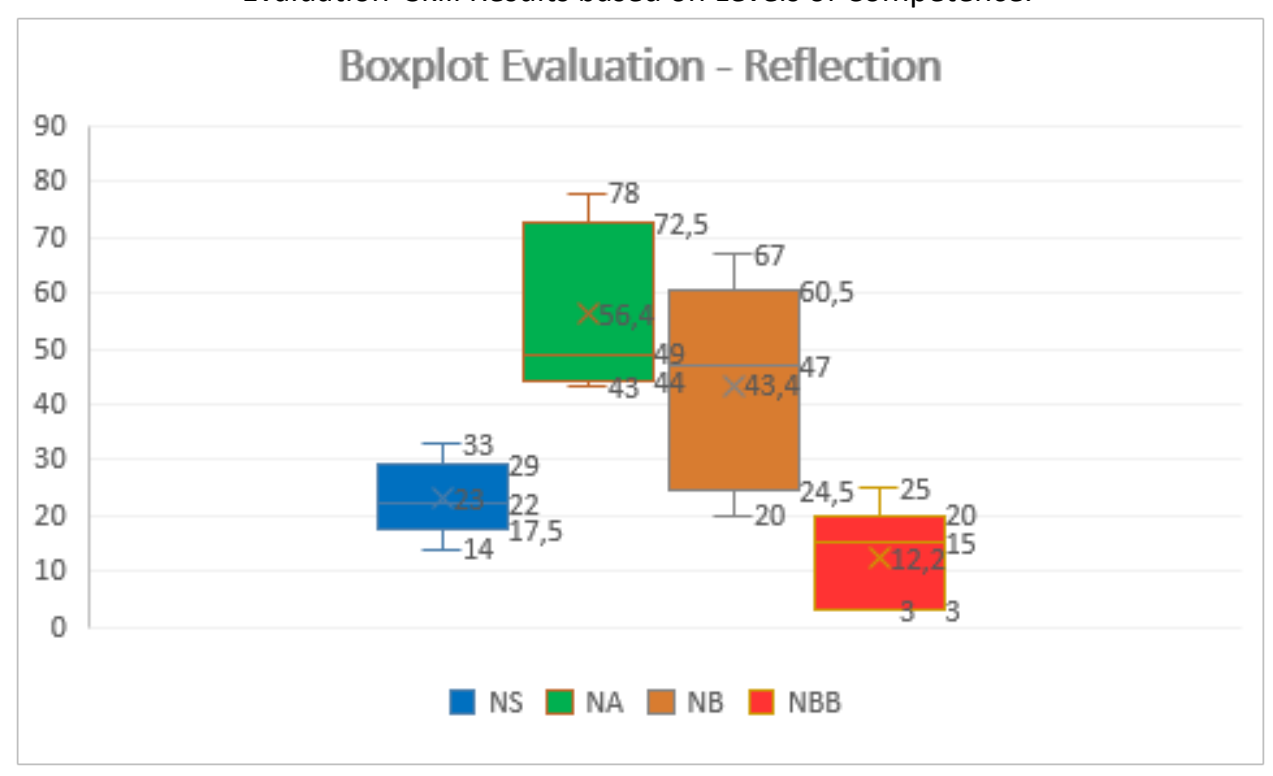

Source: Own-preparation

Figure 10

Comparison among the Diagnostic Test and Strategies taking into account the Evaluation Skill.

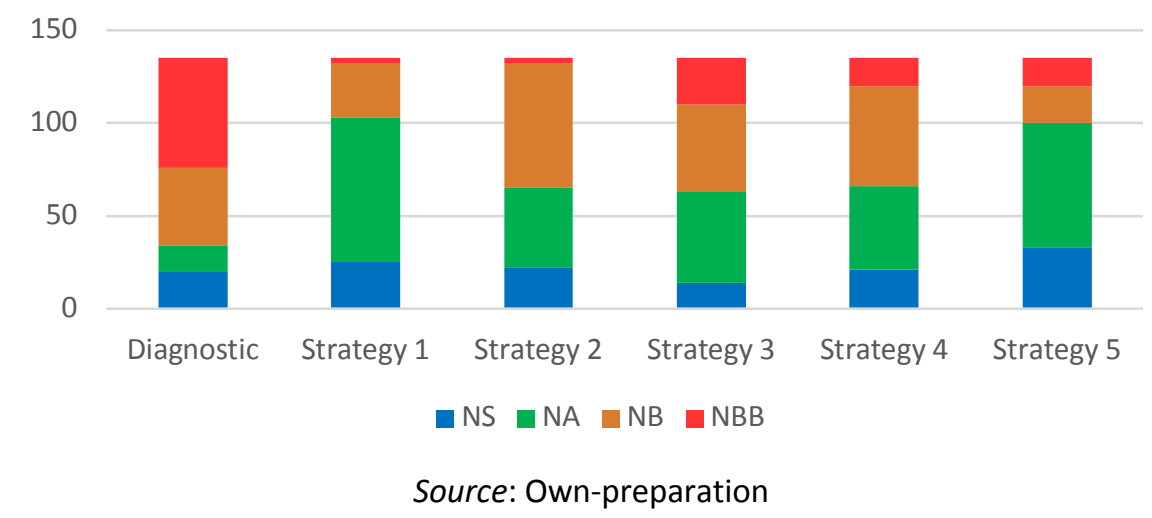


When referring to evaluation and reflection skill, $44 \%$ of the sample (59 students) obtained a low level result after taking the diagnostic test. When analyzing the bar chart, it could be observed that strategy 1 achieved the major number of students placed in the highest level range. Moreover, the low level range showed a positive change after the application of the strategies, a few students were placed there, except in strategy 3 (opinion article).

The boxplot figure indicates that a high level was obtained again in the evaluation-reflection skill, finding that at this level, the number of students correspond to an average of 49 , being the highest of all levels. Besides, the low level presented a favorable change due to the fact that its average is the lowest of all levels.

After applying the strategies, it was observed that some students had problems with expressing opinions as in strategy 3. This means the credibility of students' arguments was not good enough and they were not expressed in a clear and concise way. Some other learners showed a good command of arguments when expressing perceptions, beliefs, judgements and opinions. Those arguments were credible due to the way in which they expressed their thoughts and ideas. It is necessary to continue with this type of strategies to reinforce this skill.

\subsection{Self-regulation skill}

Figure 11

Self-regulation Skill Results based on Levels of Competence.

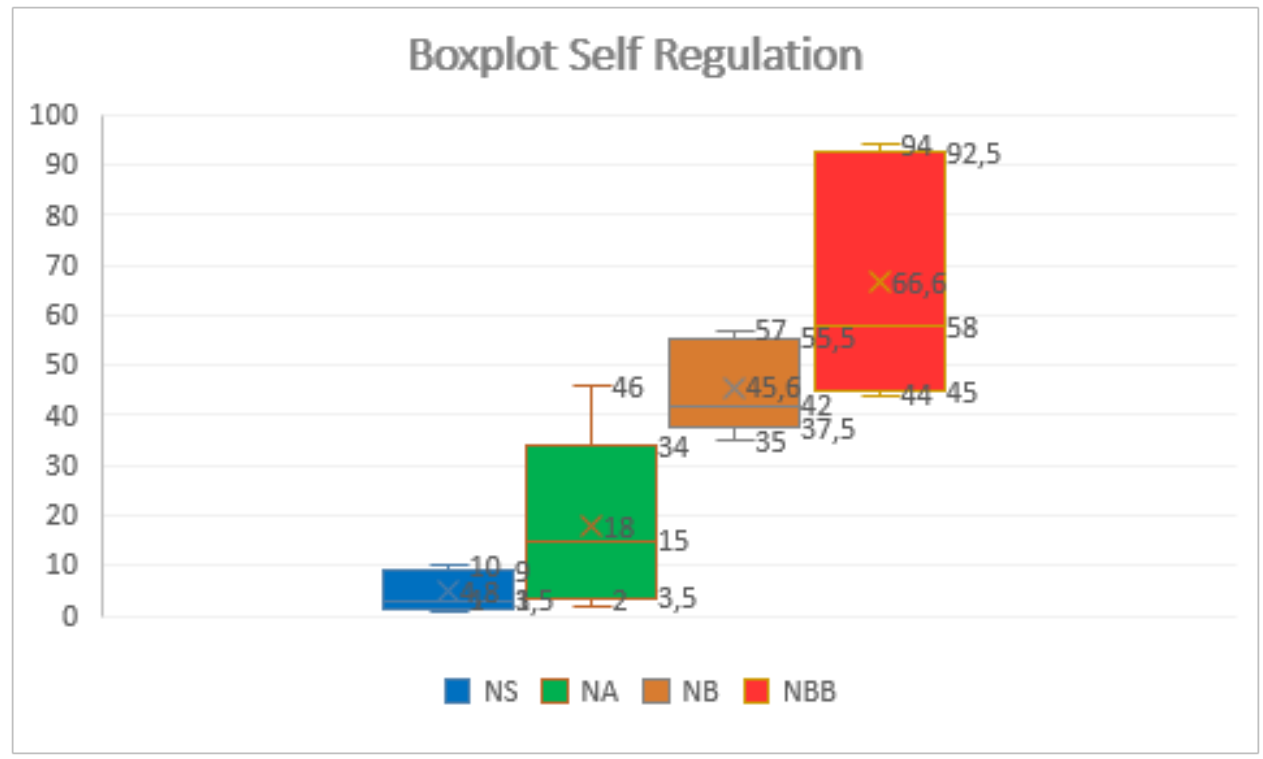

Source: Own preparation

Figure 12

Comparison among the Diagnostic Test and Strategies taking into account the Self-regulation Skill.

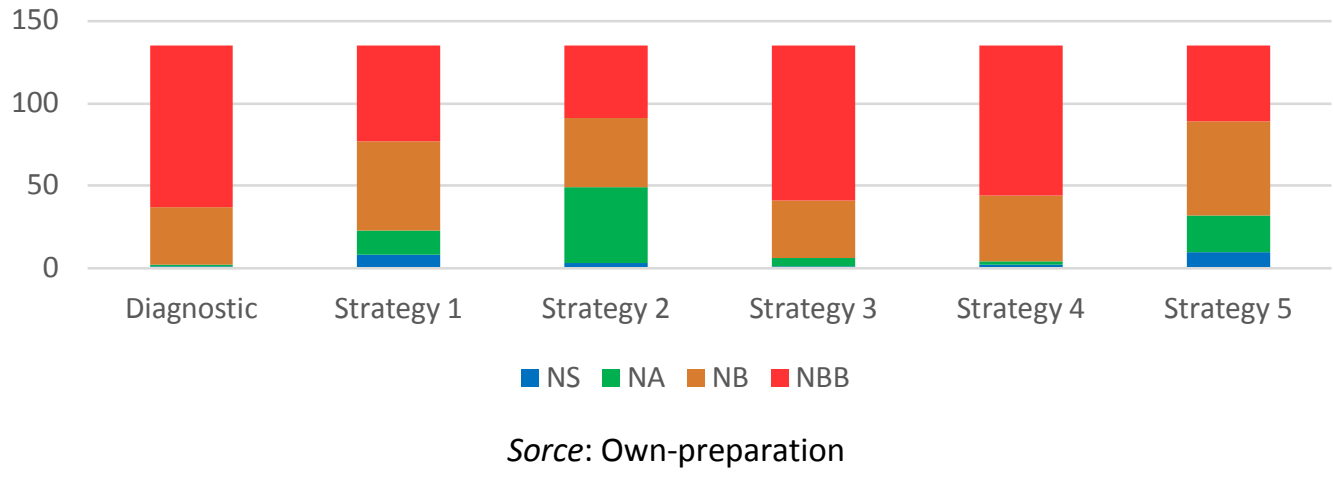


After applying the diagnostic test, 89 of 135 students (76\% of the target population) reached a low level result in the self-regulation skill. The bar diagram revealed that once strategies were applied the low level range got the major number of students in each one of them, followed by the basic level that presented an increase in each one of the five strategies.

The boxplot figure points out that the major number of students were placed in the low level range, presenting an average of 67 students, reaching a maximum level of 94 freshmen. Although some students achieved an improvement in the basic level, they have to continue developing their capacity to self-evaluate and evaluate everything around them. That is to say, that learners should plan, monitor, and assess their own performance.

We agree with Facione's thought when he mentions that self-regulation is a self- consciously monitor of a person's cognitive activities. This ability is not easy to develop because one needs "applying skills in analysis, and evaluation to one's own inferential judgements with a view toward questioning, confirming, validating, or correcting either one's reasoning or one's results" (Facione, 2007)

\section{Conclusions}

The diagnostic test evidenced that more than $40 \%$ of the target population were placed in a low performance level in all competences in regard to the development of reading comprehension and critical thinking skills. However, after applying the pedagogical strategies, the results confirmed that there was a significant improvement in students'performance, specially in the explanation ability in which the high level range evidenced the major positive change with an average of 72 students placed in it.

Furthermore, it is necessary to point out that strategy 1 (video) was the strategy in which students achieved the best results in the majority of competences, placing them in the high or superior level range. Although the selfregulation strategy got an improvement, it was the one in which more students were placed in the low and basic levels.

As educators we agree that we should develop the higher order intellectual abilities of the students across the academic disciplines because only in that way, they could be successful not only in their personal life but also when solving poblems in their contexts, making decisions, and formulating inferences as Halpen (1998) mentions in his study. We also believe that critical thinking is a way of thinking about any kind of subject, content, or problem by skillfully taking charge of structures inherent in thought. These are ways in which educators can contribute to the development of critical thinking skills.

On the other hand, if we compare Molly's results (2014), in which she reported low satisfactory improvement of students, in reasoning and reading during the four years of higher education, it can be said that this study contributed to develop reasoning and critical thinking used while doing the reading process. This is why, it is relevant to continue doing researches in this field to strengthen the critical thinking skills of students.

\section{Referencias bibliográficas}

Aguilar, M. (2000) Creatividad, pensamiento crítico y valores: una mirada diferente en la Educación .Creativity, critical thinking and values: a different look at education. Magistralis Puebla. Vol. 10(18),115-127.

Molly,W. (ed).(2014) Un libro es un amigo. Gráficas Lope Salamanca.

Bardin, L. (1996) Análisis de contenido. 2ª ed.

Cassany, D. (2003) Aproximaciones a la lectura crítica: Teoría, ejemplos y reflexiones. Hernández, Fernández, Baptista (2014) Investigación cuantitativa, cualitativa y mixta. Retrieved from https://recursos.ucol.mx/tesis/investigacion.php 
Facione, P. (1990) Critical thinking: a statement of expert consensus for purposes of educational assessment and instruction. Research findings and recommendations. Newark, DE: American Philosophical Association.

Facione, P. (2007) Pensamiento crítico. ¿Qué es y porque es importante? California: Editorial Insight Assessment.

Facione, P. (2013). Critical thinking: what it is and why it counts. Retrieved from

http://www.insightassessment.com/CT-Resources/Critical-Thinking-What-It-Isand-Why-It-Counts.

García, M.G (2016) Desde la didáctica no parametral. Estrategia Pedagógica para desarrollar el Pensamiento Crítico. Revista Educación.

Halpern, D. (1998). Teaching critical thinking for transfer across domains: dispositions, skills, structure training, and metacognitive monitoring. American Psychologist, 53(4), 449-455.

Colombia, Instituto Colombiano para la Evaluación de la Educación (2013). IV International Seminar on research in the quality of education.

Colombia, Instituto Colombiano para la Evaluación de la Educación (2018). Cuadernillo de preguntas Saber 11. Prueba de lectura crítica. Retrieved from https://www.icfes.gov.co/documents/20143/1150353/Cuadernillo+de+preguntas+Saber-11-lecturacritica.pdf/466ce032-0e1e-98c4-05ed-1b4edd348549.

Krippendorf, K. (2013). Content Analysis: An Introduction to its Methodology. Los Angeles. London, Sage.

Lipman, M. (1995) Inquiry: Critical Thinking Across the Disciplines 15(2),37-41.

Colombia, Ministerio de Educación Nacional. Decree 1290 from 2009. Reading comprehension guidelines.

Monje, C. (2011) Metodología de la Investigación Cuantitativa y Cualitativa. Universidad Surcolombiana,10-18.

Paul, R., \& Elder, L. (2004). Critical thinking ... and the art of close reading, Part III. Journal of Developmental Education, 28(1), 36-37. Retrieved from Academic Search Premier database. (AAT 14576885).

Rencher, A. (ed). (2002) Methods of Multivariate Analysis. 2a (ed.). Wiley online library. Retrieved from https://onlinelibrary.wiley.com/doi/book/10.1002/0471271357.

Sternberg, R. (2003). Four alternative futures for education in the United States: it's our choice. School Psychology Quarterly, 18(4), 431-445. Retrieved from ProQuest Education Journal database. (AAT 611229291) Macgraw Hill.

Taylor, J. (2012). Philosophical teaching will get students thinking for themselves again. The Guardian. Retrieved from https://tinyurl.com/ybsn4de6.

Tae,K.K,(2015) T-test as a parametric stadistics. Retrieved from https://www.researchgate.net/publication/285370032_T_test_as_a_parametric_statistic/link/566620680 $8 \mathrm{ae} 418 \mathrm{a} 786 \mathrm{f} 3 \mathrm{cf} 3 /$ download.

Wilson, E. (1997). The automatic generation of CALL exercises from general corpora. In A., Wichmann, S., Fligelstone, T., McEnery, \& G., Knowles (Eds.) (pp. 116-130). Teaching and Language Corpora. Harlow, England: Addison Wesley Longman.

Whiting, L (2008) Semi-structured interviews: guidance for novice researchers. Retrieved from https://go.gale.com/ps/anonymous?id=GALE\%7CA175630465\&sid=googleScholar\&v=2.1\&it=r\&linkaccess $=a b s \& i s s n=00296570 \& p=H R C A \& s w=w$

Esta obra está bajo una Licencia Creative Commons Attribución-NoCommercial 4.0 International 